\title{
SARS-Cov2: a meta-analysis of symptom distribution by continent in 7310 adult COVID-19 infected patients
}

\author{
Hitesh Singhavi ${ }^{1} \cdot$ Ameya Pai $^{2} \cdot$ Manish Mair $^{3}$ (D) Jinesh Singhavi ${ }^{1}$. \\ Prachi Gandhi $^{4} \cdot$ Andrew Baker $^{3} \cdot$ Sudip Das $^{3} \cdot$ Sanjeev Kumar ${ }^{3} \cdot$ Peter Conboy $^{3}$
}

Received: 4 August 2020/Accepted: 20 May 2021/Published online: 9 June 2021

(C) Indian Virological Society 2021

\begin{abstract}
There is recent evidence that suggests that there are multiple strains of coronavirus in different parts of the world. Moreover, scientist have noted multiple mutations and postulated that these changes might increase the infective rate of the virus. However literature on varying severity of disease based on these strains is absent. In this meta-analysis, we have made an attempt to correlate the symptoms in different continents with respect to various studied strains of virus. We searched three databases, PubMed, EMBASE and EMCARE to identify studies reporting symptoms of COVID-19. All articles published between December 2019 and May 2020 was included in this meta-analysis. A total of 56 studies consisted of 7310 patients were included in the meta-analysis. Mean age of patients varied from 22 to 69.8 years. The pooled proportion of male patients was 52\%. Highest incidence of fever $(76 \%)$ and cough $(56 \%)$ was noted in Chinese population. Sore throat (29\%) was most common in Asian population. Upper respiratory tract symptom like Rhinorrhoea, Anosmia and dysgeusia $(32 \%, 47 \%$ and 39\%) were well documented in European population as compared to the other continents. Nausea and diarrhoea were more common in
\end{abstract}

Supplementary Information The online version contains supplementary material available at https://doi.org/10.1007/s13337021-00699-y.

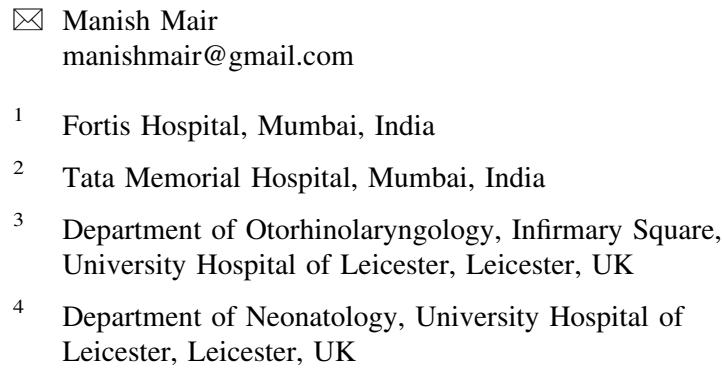

European $(17 \%, 19 \%)$ and Australian $(12 \%, 16 \%)$ population. Dyspnoea and fatigue were consistently similar in all the continents. We postulate that different mutations in COVID-19 virus may vary its pathogenicity and screening symptoms across all the continents should be not be generalised but continent-specific.

Keywords Symptoms · COVID-19 - SARS-Cov2 ·

Diagnosis $\cdot$ Mutations $\cdot$ Continents

\section{Introduction}

Coronoviruses are important pathogens affecting humans and animals. In December 2019, there was a cluster of pneumonia cases identified in Wuhan, a city in the Hubei Province of China. The causative organism was a novel coronavirus. This virus was named in February 2020 by the World Health Organization (WHO) as COVID-19. COVID-19 infection has affected 200 countries and 6 million people as of May 2020. As per the WHO-China joint mission report consisting of 55,924 patients, $80 \%$ had mild to moderate disease, while $13.8 \%$ developed severe disease and $6.1 \%$ required intensive care. It is also suggested that severe events like mortality is mainly seen in patients more than 60 years old with associated comorbidities including hypertension, diabetes, chronic respiratory and cardiac disorders or cancer. There are multiple factors that make human beings susceptible to coronavirus. Firstly, the human immune system is naive to the novel virus making individuals vulnerable to infection. Secondly, the R0 (the basic reproductive ratio) varies from 2.2 to 3.9 [29] making the virus, highly transmissible. Finally, the virus has a significant mortality rate ranging between 0.5 and $15 \%$ [65]. The biological susceptibility, infective rate 
and mortality are all important to understand and consider for initiating appropriate public health planning. It has been observed that the infective rate of this virus varied significantly in different parts of the world. This might be due to the fact that lockdown measures taken by various governments were different or changes in the biological behavior of the virus. With regards to the latter, there is recent evidence that suggests that there are multiple strains of coronavirus in different parts of the world. Moreover, scientist have noted multiple mutations and postulated that these changes might increase the infective rate of the virus. Thus, there is emerging evidence regarding different strains of coronavirus, however literature on varying severity of disease based on these strains is absent. Therefore, we have performed this single arm meta-analysis looking at the severity of symptoms in different continents of the world. As the virus is mainly transmitted as droplets through upper aero-digestive tract, special emphasize is made on the upper respiratory tract symptoms.

\section{Materials and methods}

\section{Search strategy and selection criteria}

PRISMA guidelines were followed while conducting this meta-analysis [30]. We searched three databases, PubMed, EMBASE and EMCARE to identify studies reporting upper respiratory tract symptoms of COVID-19. All articles published between December 2019 and May 2020 were included in this meta-analysis. We used the following search terms: "COVID-19", "SARS-CoV-2" and "coronavirus" in conjunction with "otorhinolaryngological manifestation" "ENT", "ear" or oto, "nose" or nasal or rhinorrhea, "throat" or upper aerodigestive tract, "oral cavity", "pharynx", "larynx", "hearing", "vertigo", "head and neck", "taste", "olfaction" and "symptoms". Boolean operators (NOT, AND, OR) were also used in succession to narrow and broaden the search. The references of all studies were also searched for any possible additional publications. Case reports and paediatric studies were excluded. Only those symptoms which had its mention at least in one study from three different continents were analysed. The literature search was screened by two independent reviewers (MM and HS) and each study was assessed for inclusion criteria. Any disagreement between the primary reviewers was resolved by consulting a third investigator (AP).

\section{Data extraction and analysis}

The data was extracted by three different authors (MM, AP and HS) independently. The extracted data included first author, publication time, study designs, city, number of COVID-19 patients, mean or median age of patients, clinical symptoms, computed tomography (CT) findings and fatality of COVID-19 patients. The extracted data was checked by another author (JS). All included literature was evaluated using the Newcastle-Ottawa Scale (NOS) [51]. The highest quality of the literature was 9 stars and the lowest 0 stars. It consists of 8 items with 3 subscales, and the total maximum score of these 3 subsets is 9. An overall score of $\geq 7,5-6$ and $\leq 4$ is considered as low, moderate, or high risk of bias respectively. Any disagreement between two authors was resolved through discussion with the third author.

\section{Statistics}

We performed data analyses using Stata version 12 (StataCorp. 2011. Stata Statistical Software: Release 12. College Station, TX: StataCorp LP). A random-effects metaanalysis was conducted to calculate pooled estimated prevalence with 95\% confidence intervals [3]. Subgroup analysis of the symptoms was done based on the continent where the study was conducted. $\mathrm{I}^{2}$ test was used for assessing the heterogeneity between studies and values of $25 \%, 50 \%$, and $75 \%$ suggested low, moderate, and high heterogeneity, respectively [18].

\section{Results}

Based on our search strategy, 1325 publications were evaluated. Of these, 431 publications had duplicate entries. Among the remaining records, 692 were excluded after screening their titles and abstracts (Fig. 1). We assessed the eligibility of 202 full-text papers. In all, 56 studies consisted of 7310 patients which were included in the metaanalysis. Supplementary Table 1 summarizes characteristics of included studies. We found six studies from Asia (excluding China), one from Australia, nine studies from Europe, three studies from United States of America and 37 studies from China. The number of patients included in various eligible studies varied from 2 to 1099. Mean or median age of patients varied from 22 to 69.8 years. Among the included studies, one study had medical workers only and two studies had pregnant women.

\section{Pooled prevalence based on meta-analysis}

The pooled proportion of male patients was $52 \%$ (0.43-0.62). Among the eligible studies, 2 (3.57\%) of 56 studies were rated as high risk of bias [11, 44], and 54 studies $(96.42 \%)$ as moderate $[1,4,5,7-11,13-17$ 


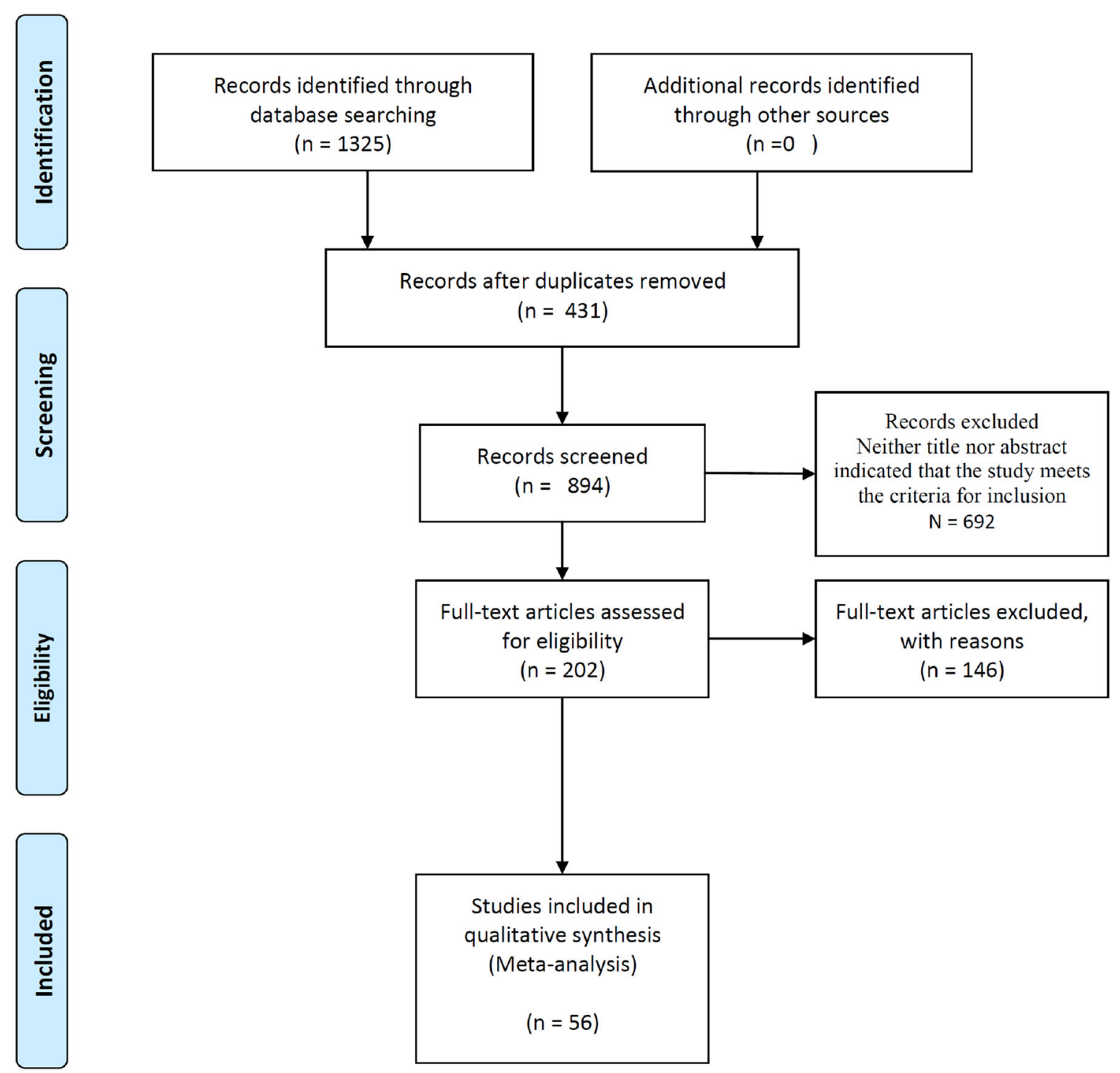

Fig. 1 Diagram shows process for selecting studies that were included in meta-analysis

, 19-25, 27, 28, 31-36, 38, 39, 41-48, 50, 52-59, 61-64] risk of bias (Supplementary Table 1).

\section{Comparison of various symptoms in different part of the world (Supplementary Table 2)}

Fever The highest incidence of fever was noted among the Chinese population (76\%) followed by Europe $(56 \%)$. Other continents like USA (34\%), Asia (36\%) and Australia $(37 \%)$ had a lower proportion of patients with fever (Fig. 2).

Cough Patients in China (57\%) and Europe (49\%) had higher incidence of cough closely followed by USA (38\%). Least amount of cough was seen in Asian (24\%) population (Fig. 3).
Fatigue Fatigue was reported in all the continents ranging from 20 to $33 \%$ except for Australia which had only $7 \%$ of the patients reporting the same.

Sore throat Asian patients had highest proportion of sore throat $(29 \%)$ but this symptom was least common in Americans (7\%). It is important to note that only $12 \%$ of Chinese population had sore throat.

Dyspnoea This symptom was similar in all the continents with highest prevalence in China (22\%) and least in Asia $(11 \%)$.

Rhinorrhoea, Anosmia and loss of taste These three symptoms were common in Europe (32\%, 47\% and 39\%) followed by USA. However, a very low percentage of patients in China $(5 \%, 5 \%, 6 \%)$ and Asia $(2 \%, 12 \%, 6 \%)$ had this symptoms. Headache also had similar distribution 


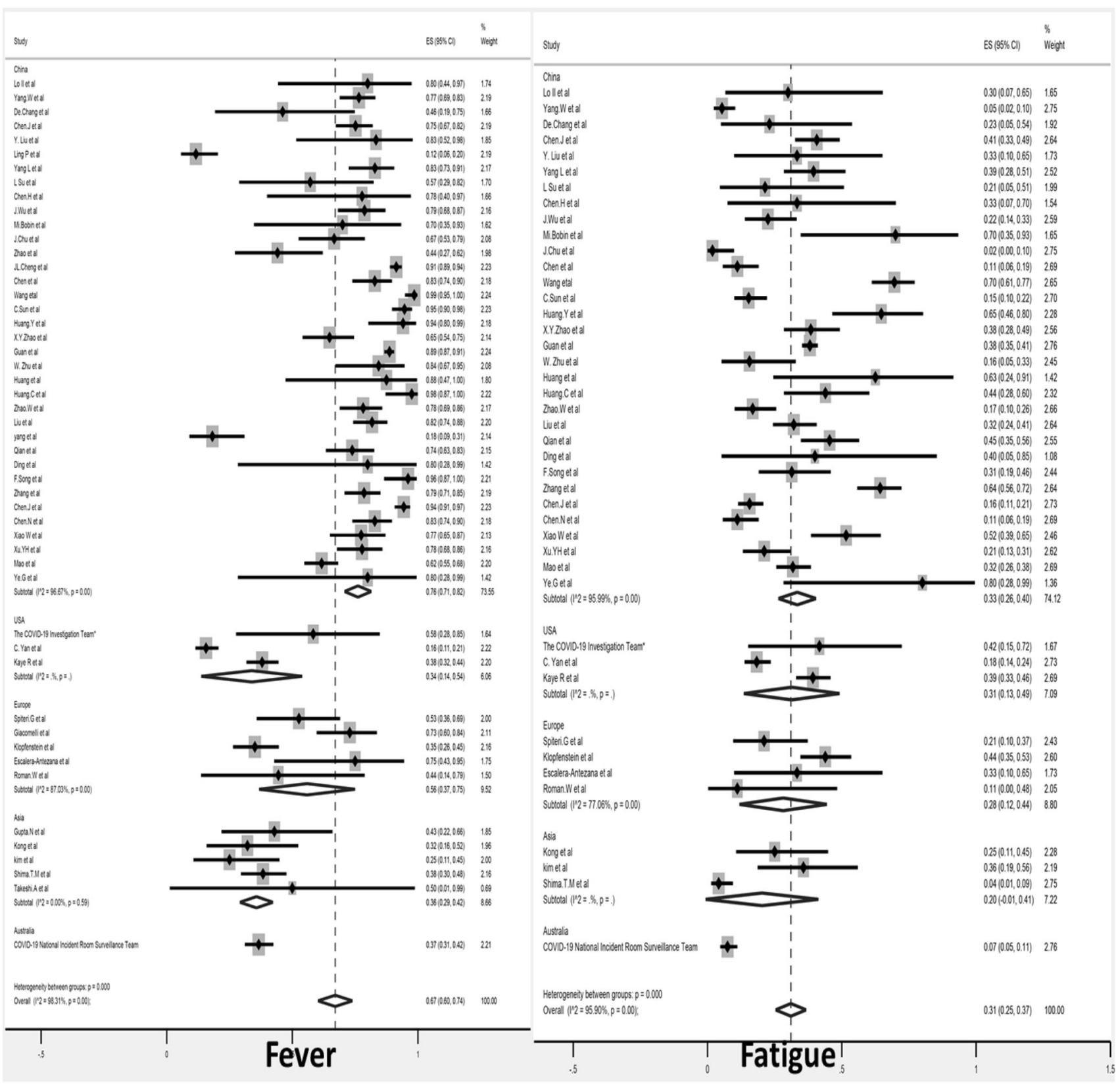

Fig. 2 Pooled prevalence of generalized symptoms in COVID-19 positive patients as per different continents

and this was more common in Europe than any other continent (Fig. 4).

Nausea and Diarrhoea Europe (17\%, 19\%) and Australia $(12 \%, 16 \%)$ had similar proportions of patients with nausea and diarrhoea. These symptoms were uncommon amongst Americans $(6 \%, 7 \%)$ and Chinese $(7 \%, 8 \%)$ populations.

Comorbidities The highest number of hypertensive $(21 \%)$ and diabetic $(8 \%)$ patients were seen in Chinese populations followed by the rest of Asia $(10 \%, 9 \%)$. A very small percentage of patients had these comorbidities in America $(3 \%, 2 \%)$ and Europe $(7 \%, 2 \%)$.
Changes in CT scan A significant number of patients in America (92\%) had changes identified on CT imaging, while only $35 \%$ of the patients in Asia had CT changes. A majority (82\%) of COVID-19 infected Chinese patients had CT changes (Fig. 5).

\section{Heterogeneity in the meta-analysis}

The variation across studies is assessed using I2 statistics (Supplementary Table 2). There is significant inter-study heterogeneity and variation across studies for most of the symptom analysis. 


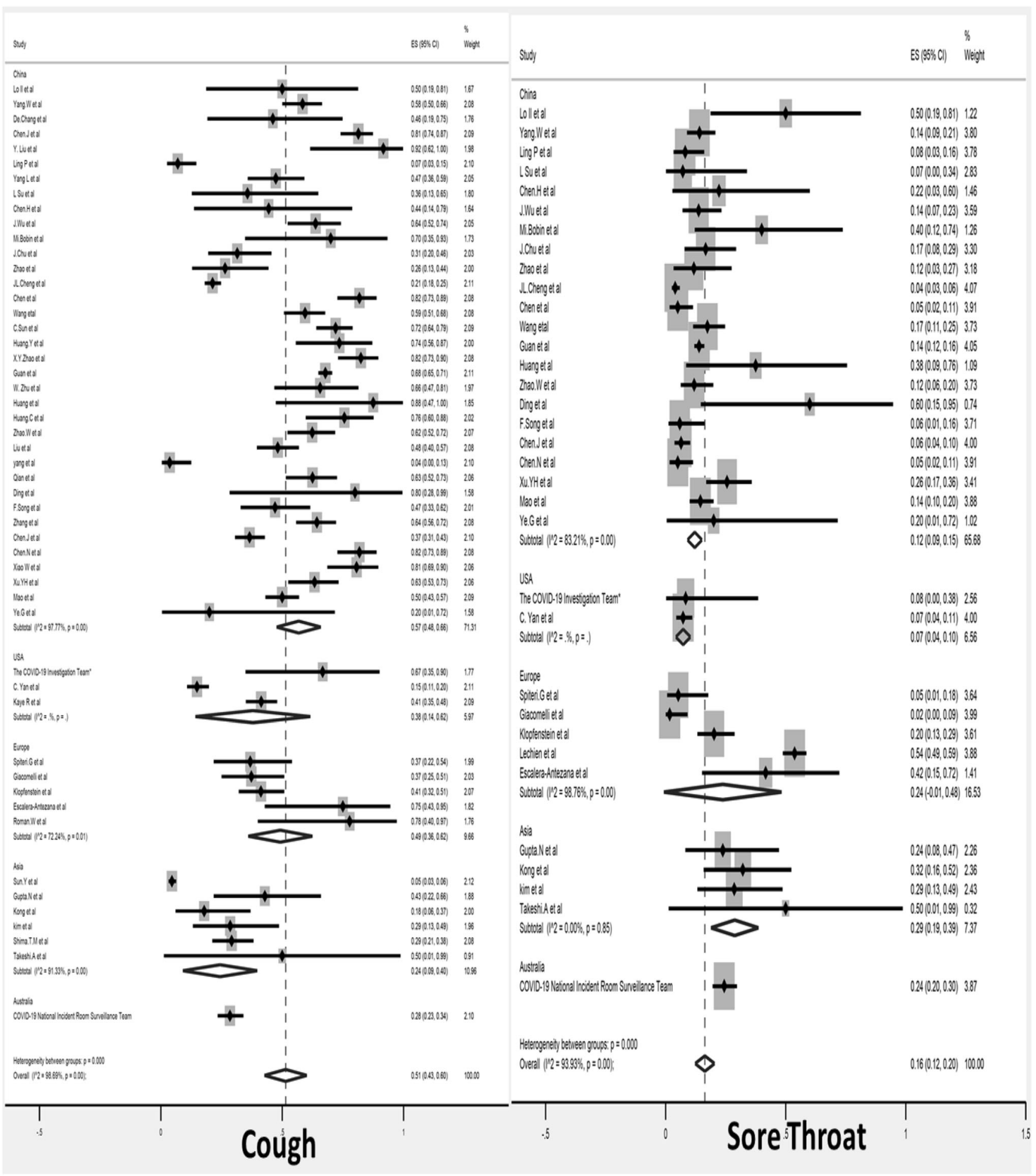

Fig. 3 Pooled prevalence of upper respiratory tract symptoms in COVID-19 positive patients as per different continents

\section{Discussion}

The enveloped RNA beta-coronavirus (Sarbecovirus subgenus) has multiple members and SARS-CoV-2 is the seventh member of this subgroup [66] Members like
HKU1, NL63, OC43 and 229E cause mild symptoms, while SARS-CoV-2, SARS-CoV and MERS-CoV can cause severe disease [12]. The transmembrane spike (S) glycoprotein mediates the entry of virus into the host cells. The S protein consists of two domains: S1 for binding 


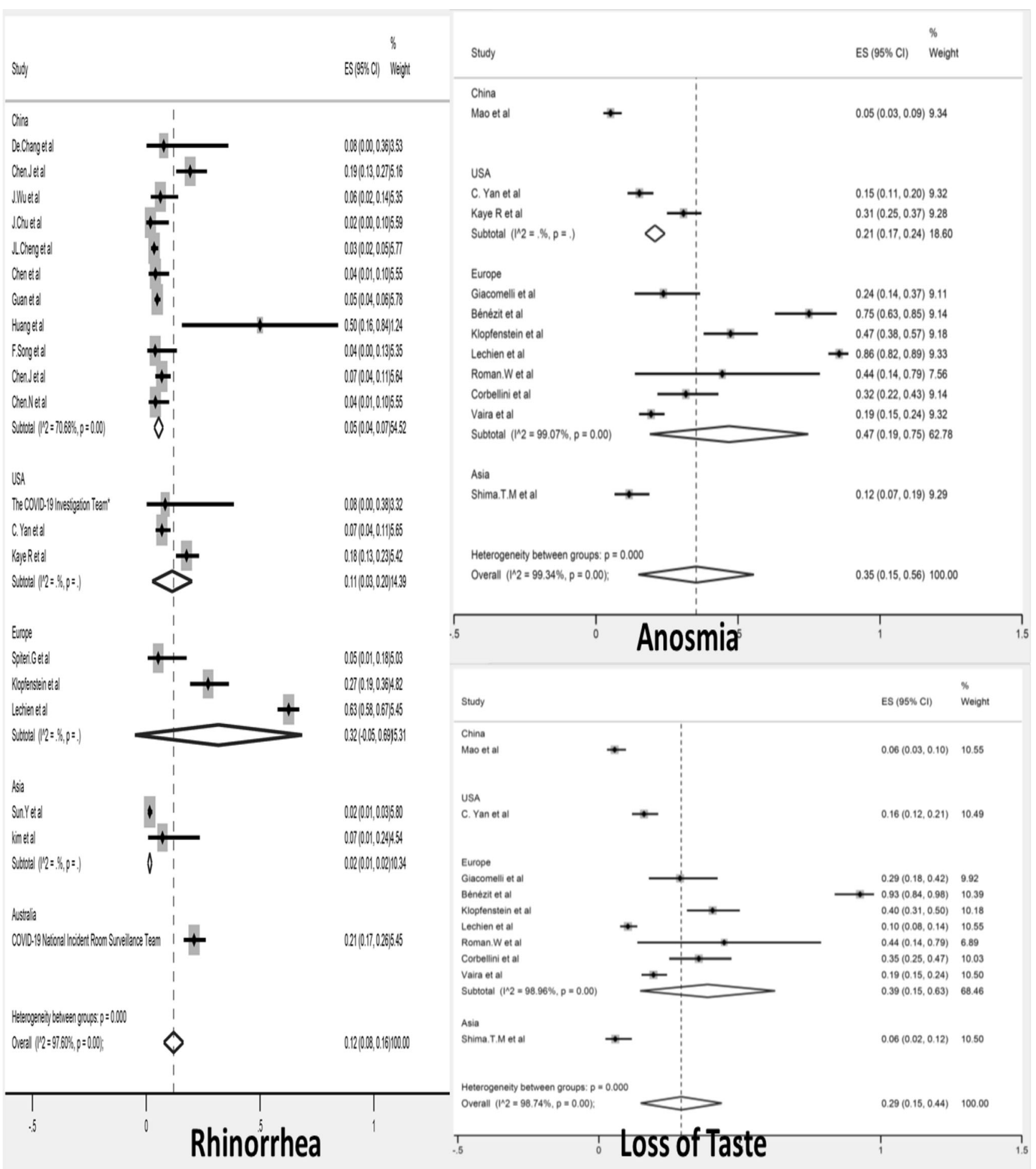

Fig. 4 Pooled prevalence of other respiratory tract symptoms in COVID-19 positive patients as per different continents

to the host cell receptor and S2 for fusion of the viral and host membranes [49]. It is important to note that SARS$\mathrm{CoV}-2$ uses the angiotensin converting enzyme 2 (ACE2) to enter host cells [49]. The expression of ACE2 is mainly in nasal epithelial cells and lung. Moreover, these receptors were also seen in spermatogonia, leydig, sertoli, gastric, duodenal, and rectal epithelial cells [50, 55, 65]. This S-protein is one of the most variable genomic parts of the virus and there is a possibility of positive selection in it $[50,65]$. Recent literature suggests the possibility of 


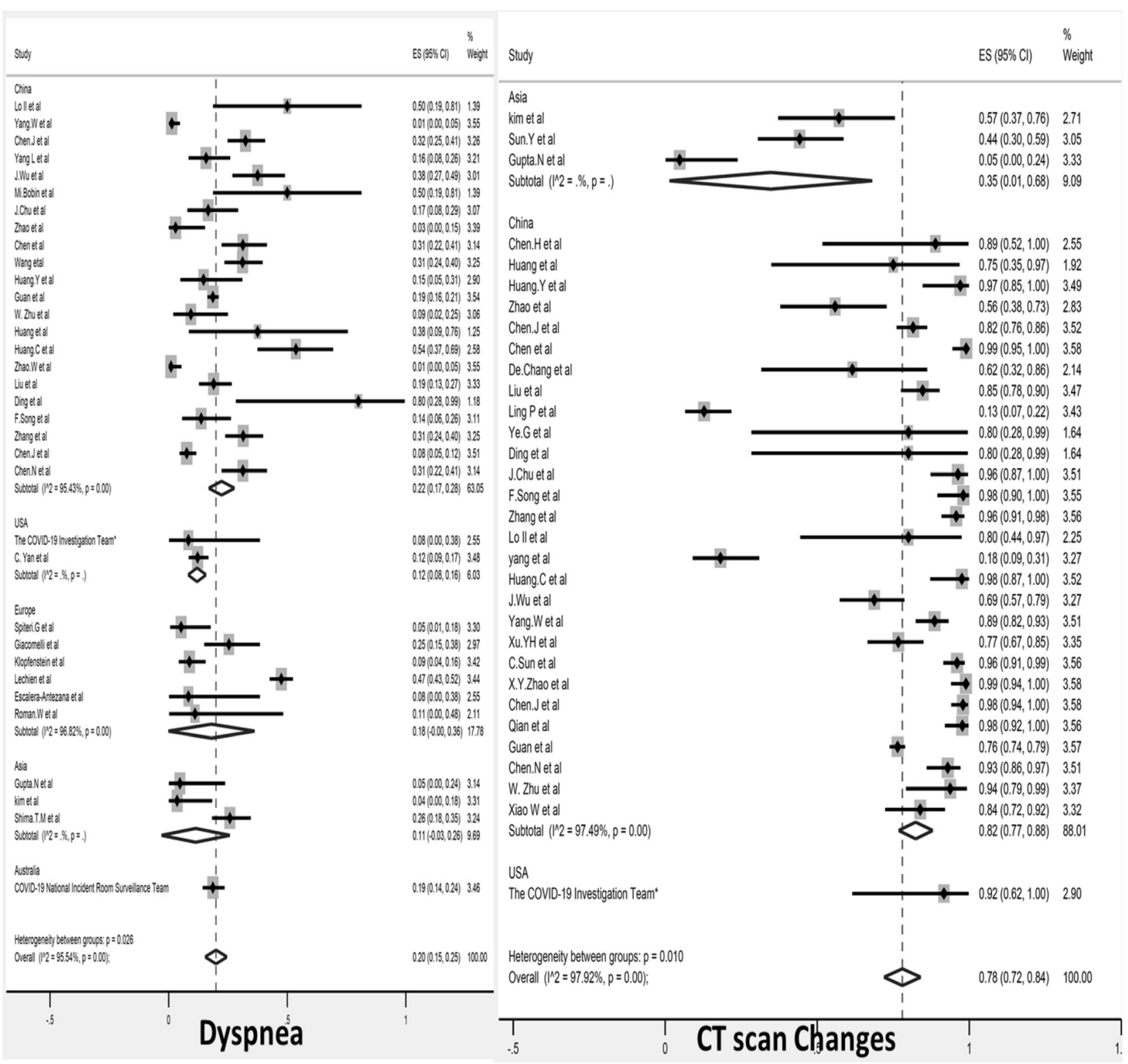

Fig. 5 Pooled prevalence of dyspnea and computed tomography (CT) changes in COVID-19 positive patients as per different continents

mutations in the novel coronavirus and presence of different strains of virus in different parts of the world. Inspite of this diversity, it is not known whether these mutations have any real functional impact on the pathogenicity of SARS-CoV-2. We performed this meta-analysis to understand whether there is any differential presentation of symptoms in Covid-19 patients all around the world [26].

A study from Los Alamos National Laboratory suggested there are fourteen mutations that are accumulating in the Spike protein. These mutations may confer selective advantage to the virus against an intervention. Among the identified mutations, the Spike D614G mutation is of immediate concern. It is postulated that a virus with this mutation is spreading rapidly in Europe and other parts of the world due to its high transmission rate, forming the dominant virus in the environment. These mutations have important implications for SARS-CoV-2 transmission, pathogenesis and immune interventions. In North America, infections were initiated with D614 but gradually by early March G614 was introduced into both Canada and the USA. Asian samples mainly had D614 original Wuhan virus which is gradually changing to G614 and expanding. As this mutation is in on the surface of the spike protein protomer, where it can form contacts with the neighboring protomer, it leads to high transmission rate [26]. Separate research from the Clinical Research Center for Infectious 
Diseases in China suggested 6 diverse mutations in 11 patient viral isolates. They also found that these mutations can lead to differential cytopathic effects and viral load as high as 270 -fold, when infecting Vero-E6 cells. Therefore, it is possible that these mutations may bring changes in the pathogenicity of the virus [60].

We found that most of the generalized symptoms like fever, cough, and fatigue were commonest in China. The World Health Organization-China Joint Mission report on Coronavirus Disease 2019 based on 55,924 patients found fever $(88 \%)$ to be the commonest symptom. However prevalence of fever was lower in Asian patients (36\%) as compared to other continents. Thus, the former dictum of screening patients based only on fever would give far more false negative results [37]. Higher frequency of sore throat in the Asian population is almost on a par with fever and thus, it could be an important symptom which needs to be considered during screening. However, upper respiratory tract infections like rhinorrhea, anosmia, loss of taste, nausea and diarrhoea are more common in Europe. This correlates well as ACE-2 receptors to which SARS-CoV2 virus binds, are mainly present at these upper respiratory tract sites. As Europe is postulated to be infected with G614 mutation which leads to higher viral load and infection rate, these particular upper respiratory tract symptoms are likely to be more common in Europe as shown in our study.

CT changes in the lung are mainly absent during early COVID-19 infection and scan changes may correlate with the severity of the disease. Literature suggests that only $3 \%$ of patients with severe COVID -19 infection have a normal initial CXR or CT [16] in a series of 121 symptomatic patients. CT scan changes were less common in the first two days of infection (44\%), while at 3-5 days, $91 \%$ and 6-12 days, 96\% patients showed CT changes [6]. The most common initial CT findings of COVID-19 pneumonia are bilateral, subpleural ground glass opacity, ill-defined margins with a slight right lower lobe predilection [40]. We found that the $\mathrm{CT}$ scan changes were more common among Americans and Chinese populations while Asian populations showed changes in $35 \%$ of the cases. However, a meta-analysis consisting of 13 studies with 2,738 participantsby Bao et al. found abnormal CT imaging features in 2,386 patients. The pooled positive rate of the $\mathrm{CT}$ imaging was $89.76 \%$ [2]. All the studies included in this metaanalysis by Bao et al. were from China. We have evaluated 28 studies reporting CT scan findings in the Chinese population and found $82 \%$ of the cases had abnormalities. But, it should be kept in mind that abnormal CT findings in Asian population were seen in only $35 \%$ of the cases... There is emerging evidence that CT scan could be used as a diagnostic tool for COVID-19 infection. However, as the CT changes among the COVID-19 patients is not uniform all around the world, the applicability of using CT scan as a diagnostic toil must be globally explored before making it a standard of practice. Thus further research is warranted on this topic.

There are a lot of limitations in this meta-analysis as most of the included studies are retrospective in nature. In addition, correlation between the possible strains and symptoms can just be postulated. Unfortunately, other factors like host genetics, general health status of populations, environmental factors, economic factors that determine access to healthcare is difficult to take into consideration which may impact variation in symptomatology of COVID-19 infection across the world. However, this is the only study looking at the continent-based difference of the symptoms among the Covid-19 infected patients. This study is especially important with new numerous various mutants of this virus detected all around the world.

European patients had higher incidence of upper respiratory tract symptoms like Rhinorrhoea, Anosmia and loss of taste. Generalized symptoms like fever, cough and Dyspnoea were more commonly reported among the Chinese populations. One must understand that it is difficult to make assertive conclusions based on the available data in the middle of the ongoing pandemic as there are multiple other factors which might play a role as mentioned in the limitation. There is a need for further studies which can help us understand the differential pathogenicity of the virus based on its ongoing mutations.

Funding No source of funding.

\section{Declarations}

Conflict of interest The authors declare that they have no conflict of interest.

\section{References}

1. Arashiro T, Furukawa K, Nakamura A. COVID-19 in 2 persons with mild upper respiratory symptoms on a cruise ship, Japan. Emerg Infect. 2020.

2. Bao C, Liu X, Zhang H, Li Y, Liu J. Coronavirus disease 2019 (COVID-19) CT findings: a systematic review and meta-analysis. J Am Coll Radiol. 2020;17(6):701-9. https://doi.org/10.1016/j. jacr.2020.03.006.

3. Barendregt JJ, Doi SA, Lee YY, Norman RE, Vos T. Metaanalysis of prevalence. J Epidemiol Community Health. 2013;67(11):974-8.

4. Beltrán-Corbellini Á, Chico-García JL, Martínez-Poles J, Rodríguez-Jorge F, Natera-Villalba E, Gómez-Corral J, et al. Acuteonset smell and taste disorders in the context of Covid-19: a pilot multicenter PCR-based case-control study. Eur J Neurol. 2020;27(9):e33. https://doi.org/10.1111/ene.14357. 
5. Bénézit F, Le Turnier P, Declerck C, Paillé C, Revest M, Dubée $\mathrm{V}$, et al. Utility of hyposmia and hypogeusia for the diagnosis of COVID-19. Lancet Infect Dis. 2020. https://doi.org/10.1016/ S1473-3099(20)30293-0

6. Bernheim A, Mei X, Huang M, Yang Y, Fayad ZA, Zhang N, et al. Chest CT findings in coronavirus disease-19 (COVID-19): relationship to duration of infection. Radiology. 2020;2020:200463.

7. Chang D, Lin M, Wei L, Xie L, Zhu G, Cruz CSD, et al. Epidemiologic and clinical characteristics of novel coronavirus infections involving 13 patients outside Wuhan, China. JAMA. 2020;323(11):1092-3.

8. Chen J, Qi T, Liu L, Ling Y, Qian Z, Li T, et al. Clinical progression of patients with COVID-19 in Shanghai. China. J Infect. 2020;80(5):e1-6. https://doi.org/10.1016/j.jinf.2020.03.004.

9. Chen N, Zhou M, Dong X, Qu J, Gong F, Han Y, et al. Epidemiological and clinical characteristics of 99 cases of 2019 novel coronavirus pneumonia in Wuhan, China: a descriptive study. Lancet. 2020;395(10223):507-13.

10. Cheng JL, Huang C, Zhang GJ, Liu DW, Li P, Lu CY, et al. Epidemiological characteristics of novel coronavirus pneumonia in Henan. Zhonghua Jie He He Hu Xi Za Zhi Zhonghua Jiehe He Huxi Zazhi Chin J Tuberc Respir Dis. 2020;43:E027-E027.

11. Chu J, Yang N, Wei Y, Yue H, Zhang F, Zhao J, et al. Clinical characteristics of 54 medical staff with COVID-19: a retrospective study in a single center in Wuhan, China. J Med Virol. 2020;92(7):807-13. https://doi.org/10.1002/jmv.25793.

12. Corman VM, Lienau J, Witzenrath M. Coronaviruses as the cause of respiratory infections. Internist. 2019;60(11):1136-45.

13. Ding Q, Lu P, Fan Y, Xia Y, Liu M. The clinical characteristics of pneumonia patients coinfected with 2019 novel coronavirus and influenza virus in Wuhan, China. J Med Virol. 2020;92(9):1549-55. https://doi.org/10.1002/jmv.25781.

14. Escalera-Antezana JP, Lizon-Ferrufino NF, Maldonado-Alanoca A, Alarcón-De-la-Vega G, Alvarado-Arnez LE, BalderramaSaavedra MA. Clinical features of cases and a cluster of Coronavirus Disease 2019 (COVID-19) in Bolivia imported from Italy and Spain. Travel Med Infect Dis. 2020;2020:101653.

15. Giacomelli A, Pezzati L, Conti F, Bernacchia D, Siano M, Oreni L, et al. Self-reported olfactory and taste disorders in patients with severe acute respiratory coronavirus 2 infection: a crosssectional study. Clin Infect Dis. 2020;71(15):889-90.

16. Guan W, Ni Z, Hu Y, Liang W, Ou C, He J, et al. Clinical characteristics of coronavirus disease 2019 in China. N Engl J Med. 2020;382(18):1708-20.

17. Gupta N, Agrawal S, Ish P, Mishra S, Gaind R, Usha G, et al. Clinical and epidemiologic profile of the initial COVID-19 patients at a tertiary care centre in India. Monaldi Arch Chest Dis. 2020. https://doi.org/10.4081/monaldi.2020.1294.

18. Higgins JP, Thompson SG, Deeks JJ, Altman DG. Measuring inconsistency in meta-analyses. BMJ. 2003;327(7414):557-60.

19. Huang Y, Tu M, Wang S, Chen S, Zhou W, Chen D, et al. Clinical characteristics of laboratory confirmed positive cases of SARS-CoV-2 infection in Wuhan, China: a retrospective single center analysis. Travel Med Infect Dis. 2020;395(10229):1054-62.

20. Huang C, Wang Y, Li X, Ren L, Zhao J, Hu Y, et al. Clinical features of patients infected with 2019 novel coronavirus in Wuhan, China. Lancet. 2020;395(10223):497-506.

21. Huang L, Zhang X, Zhang X, Wei Z, Zhang L, Xu J, et al. Rapid asymptomatic transmission of COVID-19 during the incubation period demonstrating strong infectivity in a cluster of youngsters aged 16-23 years outside Wuhan and characteristics of young patients with COVID-19: a prospective contact-tracing study. J Infect. 2020;80(6):e1-13. https://doi.org/10.1016/j.jinf.2020.03. 006.
22. Kaye R, Chang CD, Kazahaya K, Brereton J, Denneny JC III. COVID-19 anosmia reporting tool: initial findings. Otolaryngol Neck Surg. 2020;163(1):132-4. https://doi.org/10.1177/ 0194599820922992.

23. Kim ES, Chin BS, Kang CK, Kim NJ, Kang YM, Choi J-P, et al. Clinical course and outcomes of patients with severe acute respiratory syndrome coronavirus 2 infection: a preliminary report of the first 28 patients from the Korean cohort study on COVID19. J Korean Med Sci. 2020;35(13).

24. Klopfenstein T, Toko L, Royer P-Y, Lepiller Q, Gendrin V, Zayet S. Features of anosmia in COVID-19. Med Mal Infect. 2020;50(5):436-9. https://doi.org/10.1016/j.medmal.2020.04. 006.

25. Kong I, Park Y, Woo Y, Lee J, Cha J, Choi J, et al. Early epidemiological and clinical characteristics of 28 cases of coronavirus disease in South Korea. Osong Public Health Res Perspect. 2020;11(1):8-14.

26. Korber B, Fischer W, Gnanakaran SG, Yoon H, Theiler J, Abfalterer W, et al. Spike mutation pipeline reveals the emergence of a more transmissible form of SARS-CoV-2. bioRxiv. 2020.

27. Kujawski SA, Wong KK, Collins JP, Epstein L, Killerby ME, Midgley CM, et al. First 12 patients with coronavirus disease 2019 (COVID-19) in the United States. MedRxiv. 2020;861-8. https://doi.org/10.1038/s41591-020-0877-5

28. Lechien JR, Chiesa-Estomba CM, De Siati DR, Horoi M, Le Bon $\mathrm{SD}$, Rodriguez A et al. Olfactory and gustatory dysfunctions as a clinical presentation of mild-to-moderate forms of the coronavirus disease (COVID-19): a multicenter European study. Eur Arch Otorhinolaryngol. 2020;277(8):2251-61. https://doi.org/10. 1007/s00405-020-05965-1

29. Lei S, Jiang F, Su W, Chen C, Chen J, Mei W, et al. Clinical characteristics and outcomes of patients undergoing surgeries during the incubation period of COVID-19 infection. EClinicalMedicine. 2020;2020:100331.

30. Liberati A, Altman DG, Tetzlaff J, Mulrow C, Gøtzsche PC, Ioannidis JP, et al. The PRISMA statement for reporting systematic reviews and meta-analyses of studies that evaluate health care interventions: explanation and elaboration. J Clin Epidemiol. 2009;62(10):e1-34.

31. Liu K, Fang Y-Y, Deng Y, Liu W, Wang M-F, Ma J-P, et al. Clinical characteristics of novel coronavirus cases in tertiary hospitals in Hubei Province. Chin Med J (Engl). 2020;133(9):1025-31. https://doi.org/10.1097/CM9. 0000000000000744.

32. Liu Y, Liao W, Wan L, Xiang T, Zhang W. Correlation between relative nasopharyngeal virus RNA load and lymphocyte count disease severity in patients with COVID-19. Viral Immunol. 2020. https://doi.org/10.1089/vim.2020.0062.

33. Lo IL, Lio CF, Cheong HH, Lei CI, Cheong TH, Zhong X, et al. Evaluation of SARS-CoV-2 RNA shedding in clinical specimens and clinical characteristics of 10 patients with COVID-19 in Macau. Int J Biol Sci. 2020;16(10):1698.

34. Mao L, Jin H, Wang M, Hu Y, Chen S, He Q, et al. Neurologic manifestations of hospitalized patients with coronavirus disease 2019 in Wuhan. China. JAMA Neurol. 2020;77(6):683-90.

35. Mi B, Chen L, Xiong Y, Xue H, Zhou W, Liu G. Characteristics and early prognosis of COVID-19 infection in fracture patients. JBJS. 2020;102(9):750-8.

36. Moein ST, Hashemian SM, Mansourafshar B, Khorram-Tousi A, Tabarsi P, Doty RL. Smell dysfunction: a biomarker for COVID19. Int Forum Allergy Rhinol. 2020;10(8):944-50. https://doi.org/ 10.1002/alr.22587.

37. Organization WH, Organization WH. Report of the WHO-China joint mission on coronavirus disease 2019 (COVID-19). Geneva; 2020. 
38. Peng L, Liu K-Y, Xue F, Miao Y-F, Tu P-A, Zhou C. Improved early recognition of coronavirus disease-2019 (COVID-19): single-center data from a Shanghai screening hospital. Arch Iran Med. 2020;23(4):272-6.

39. Qian G-Q, Yang N-B, Ding F, Ma AHY, Wang Z-Y, Shen Y-F, et al. Epidemiologic and clinical characteristics of 91 hospitalized patients with COVID-19 in Zhejiang, China: a retrospective, multi-centre case series. QJM Int J Med. 2020;113(7):474-81. https://doi.org/10.1093/qjmed/hcaa089.

40. Shi H, Han X, Jiang N, Cao Y, Alwalid O, Gu J, et al. Radiological findings from 81 patients with COVID-19 pneumonia in Wuhan, China: a descriptive study. Lancet Infect Dis. 2020;20(4):425-34. https://doi.org/10.1016/S14733099(20)30086-4.

41. Song R, Han B, Song M, Wang L, Conlon CP, Dong T, et al. Clinical and epidemiological features of COVID-19 family clusters in Beijing. China. J Infect. 2020;81(2):e26-30. https:// doi.org/10.1016/j.jinf.2020.04.018.

42. Song F, Shi N, Shan F, Zhang Z, Shen J, Lu H, et al. Emerging 2019 novel coronavirus (2019-nCoV) pneumonia. Radiology. 2020;295(1):210-7.

43. Spiteri G, Fielding J, Diercke M, Campese C, Enouf V, Gaymard A, et al. First cases of coronavirus disease 2019 (COVID-19) in the WHO European Region, 24 January to 21 February 2020. Eurosurveillance. 2020;25(9):2000178.

44. Su L, Ma X, Yu H, Zhang Z, Bian P, Han Y, et al. The different clinical characteristics of corona virus disease cases between children and their families in China-the character of children with COVID-19. Emerg Microbes Infect. 2020;9(1):707-13.

45. Sun Y, Koh V, Marimuthu K, Ng OT, Young B, Vasoo S, et al. Epidemiological and clinical predictors of COVID-19. Clin Infect Dis. 2020;71(15):786-92. https://doi.org/10.1093/cid/ciaa322.

46. Sun C, Zhang XB, Dai Y, Xu XZ, Zhao J. Clinical analysis of 150 cases of 2019 novel coronavirus infection in Nanyang City, Henan Province. Zhonghua Jie He He Hu Xi Za Zhi Zhonghua Jiehe He Huxi Zazhi Chin J Tuberc Respir Dis. 2020;43:E042E042.

47. Team C-19 NIRS. COVID-19, Australia: epidemiology report 6 (reporting week ending 19: 00 AEDT 7 March 2020). Commun Dis Intell. 2020. https://doi.org/10.33321/cdi.2020.44.2.

48. Vaira LA, Salzano G, Deiana G, De Riu G. Anosmia and ageusia: common findings in COVID-19 patients. Laryngoscope. 2020;130(11):E695. https://doi.org/10.1002/lary.28753.

49. Walls AC, Park Y-J, Tortorici MA, Wall A, McGuire AT, Veesler D. Structure, function, and antigenicity of the SARSCoV-2 spike glycoprotein. Cell. 2020;181(2):281-92.e6. https:// doi.org/10.1016/j.cell.2020.02.058.

50. Wang D, Hu B, Hu C, Zhu F, Liu X, Zhang J, et al. Clinical characteristics of 138 hospitalized patients with 2019 novel coronavirus-infected pneumonia in Wuhan, China. JAMA. 2020;323(11):1061-9.

51. Wells GA, Shea B, O'connell D, Peterson J, Welch V, Losos M, et al. The Newcastle-Ottawa Scale (NOS) for assessing the quality of nonrandomised studies in meta-analyses. 2013; 2016.

52. Wölfel R, Corman VM, Guggemos W, Seilmaier M, Zange S, Müller MA, et al. Virological assessment of hospitalized patients with COVID-2019. Nature. 2020;581(7809):465-9. https://doi. org/10.1038/s41586-020-2196-x.

53. Wu J, Liu J, Zhao X, Liu C, Wang W, Wang D, et al. Clinical characteristics of imported cases of coronavirus disease 2019 (COVID-19) in Jiangsu Province: a multicenter descriptive study.
Clin Infect Dis. 2020;71(15):706-12. https://doi.org/10.1093/cid/ ciaa199.

54. Xu Y-H, Dong J-H, An W-M, Lv X-Y, Yin X-P, Zhang J-Z, et al. Clinical and computed tomographic imaging features of novel coronavirus pneumonia caused by SARS-CoV-2. J Infect. 2020;80(4):394-400. https://doi.org/10.1016/j.jinf.2020.02.017.

55. Xu Y, Li X, Zhu B, Liang H, Fang C, Gong Y, et al. Characteristics of pediatric SARS-CoV-2 infection and potential evidence for persistent fecal viral shedding. Nat Med. 2020;26(4):502-5.

56. Xu X-W, Wu X-X, Jiang X-G, Xu K-J, Ying L-J, Ma C-L, et al. Clinical findings in a group of patients infected with the 2019 novel coronavirus (SARS-Cov-2) outside of Wuhan, China: retrospective case series. BMJ. 2020;368. https://doi.org/10.1136/ bmj.m606.

57. Yan $\mathrm{CH}$, Faraji F, Prajapati DP, Boone CE, DeConde AS. Association of chemosensory dysfunction and Covid-19 in patients presenting with influenza-like symptoms. Int Forum Allergy Rhinol. 2020;10(7):806-13. https://doi.org/10.1002/alr. 22579.

58. Yang W, Cao Q, Qin L, Wang X, Cheng Z, Pan A, et al. Clinical characteristics and imaging manifestations of the 2019 novel coronavirus disease (COVID-19): a multi-center study in Wenzhou city, Zhejiang, China. J Infect. 2020;80(4):388-93. https:// doi.org/10.1016/j.jinf.2020.02.016.

59. Yang F, Shi S, Zhu J, Shi J, Dai K, Chen X. Analysis of 92 deceased patients with COVID-19. J Med Virol. 2020;92(11):2511-5. https://doi.org/10.1002/jmv.25891.

60. Yao H-P, Lu X, Chen Q, Xu K, Chen Y, Cheng L, et al. Patientderived mutations impact pathogenicity of SARS-CoV-2. CELL20-01124. 2020. https://doi.org/10.1101/2020.04.14.20060160.

61. Ye G, Pan Z, Pan Y, Deng Q, Chen L, Li J, et al. Clinical characteristics of severe acute respiratory syndrome coronavirus 2 reactivation. J Infect. 2020;80(5):e14-7. https://doi.org/10. 1016/j.jinf.2020.03.001.

62. Zhang J, Dong X, Cao Y, Yuan Y, Yang Y, Yan Y, et al. Clinical characteristics of 140 patients infected with SARS-CoV-2 in Wuhan, China. Allergy. 2020;75(7):1730-41. https://doi.org/10. 1111/all.14238.E.

63. Zhao X-Y, Xu X-X, Yin H-S, Hu Q-M, Xiong T, Tang Y-Y, et al. Clinical characteristics of patients with 2019 coronavirus disease in a non-Wuhan area of Hubei Province, China: a retrospective study. BMC Infect Dis. 2020;20:1-8.

64. Zhao W, Zhong Z, Xie X, Yu Q, Liu J. Relation between chest $\mathrm{CT}$ findings and clinical conditions of coronavirus disease (COVID-19) pneumonia: a multicenter study. Am J Roentgenol. 2020;214(5):1072-7.

65. Zhou F, Yu T, Du R, Fan G, Liu Y, Liu Z, et al. Clinical course and risk factors for mortality of adult inpatients with COVID-19 in Wuhan, China: a retrospective cohort study. Lancet. 2020;395(10229):1054-62. https://doi.org/10.1016/S01406736(20)30566-3.

66. Zhu W, Xie K, Lu H, Xu L, Zhou S, Fang S. Initial clinical features of suspected Coronavirus Disease 2019 in two emergency departments outside of Hubei, China. J Med Virol. 2020;92(9):1525-32. https://doi.org/10.1002/jmv.25763.

Publisher's Note Springer Nature remains neutral with regard to jurisdictional claims in published maps and institutional affiliations. 